\title{
Foreword: An Archaeological Decameron-Research, Interpretation, and Engagement in the Time of Pandemic
}

\author{
Melanie Damour
}

Accepted: 26 October 2021 / Published online: 6 January 2022

(C) The Author(s) under exclusive licence to Society for Historical Archaeology 2021

For more than 60 years, the Advisory Council on Underwater Archaeology (ACUA)—beginning with its initial formation as the Council on Underwater Archaeology in 1959- has served as an international advisory body providing guidance on issues related to maritime, nautical, and underwater archaeology. Research related to these topics is presented at the Society for Historical Archaeology's (SHA) annual conference on historical and underwater archaeology. The ACUA publishes the Underwater Archaeology Proceedings, featuring papers focusing on this discipline that were presented at the SHA conference. For decades, the ACUA Proceedings has served as a reliable venue for disseminating the latest information on underwater archaeological methods and theory, and best management practices, and provides a valuable opportunity for students to publish their original research.

In 2020, the global COVID-19 pandemic forced the SHA Board to make a tough decision about the January 2021 conference: pivot to an entirely virtual format or cancel the annual conference altogether, as other scientific and professional societies opted. Faced with this dilemma, the board ultimately decided to stay the course and hold the January

\section{Damour $(\bowtie)$}

Submerged Archaeological Conservancy International, 2059 Ponderosa Place, Mandeville, LA 70448-7525,

U.S.A.

e-mail:melanie@saci.org
2021 conference virtually. Featuring prerecorded oral and poster presentations along with live panels and discussion sessions for symposia held during the January meeting, the 2021 SHA virtual conference changed the way participants "conferenced." The virtual format allowed participants to view all of the presentations and posters of interest, to engage in meaningful dialogue and dive deeper into discussions with presenters than a typical $15 \mathrm{~min}$. Q\&A period can accommodate, and facilitated more international participation, especially for students who could not afford the travel costs associated with traditional inperson attendance. The 2021 SHA virtual conference provided new opportunities, including some that were unexpected.

The post-conference call for underwater papers for the 2021 ACUA Proceedings yielded too few submittals to justify the cost of publishing the usual stand-alone bound volume. Instead of canceling the Proceedings, Annalies Corbin, the ACUA editor, contacted Kathryn Sampeck, editor of SHA's Historical Archaeology journal, to inquire whether the ACUA Proceedings papers could be published as a special section in an upcoming issue of the journal. Kathryn welcomed the ACUA underwater papers with open arms and provided the authors with an exciting opportunity to share their research with the wider SHA membership. We at ACUA are grateful for everyone's efforts to accommodate the ACUA Underwater Archaeology Proceedings under such unprecedented circumstances. 
Three articles are included in the ACUA Underwater Archaeology Proceedings section of this issue of Historical Archaeology. The article by Herrmann analyzes personal possessions found on board the 16th-century Emanuel Point shipwrecks in Pensacola Bay, Florida, to interpret their religious symbolism. A comparison is made with religious artifacts found on board the 16th-century Padre Island shipwrecks discovered in the Gulf of Mexico off the Texas coast. Details, such as the intricate designs on a gold crucifix and the evidence of repairs to a wooden cross, not only yield information on the religious symbolism of each piece, but also on their importance to the owner.

The article by Guibert, Bigot, and Botcazou provides a comprehensive overview of the archaeological investigation of a 19th-century French naval schooner in the French West Indies. Over the course of a five-year period (2015-2019), French archaeologists conducted a systematic excavation and mapping campaign to document the remains of the vessel employed as a patrol and customs ship in Guadeloupe. The vessel sank during a hurricane in 1824 and has provided valuable information about French ship construction, material culture, and the socioeconomic disparity between the officers and crew as represented by a spatial analysis of the artifact distribution. Archival research discovered original ships' design plans that served as a comparative data set for the archaeological methodology, which included analysis of hull construction, artifacts, and dendrology, as well as photogrammetry.

The third article, by Pink and Whitewright, focuses on the archaeological interpretation of a 19th-century schooner lost on the East Winner Bank near Portsmouth, UK. The authors employed archival research and archaeological documentation to inform their identification of the shipwreck as a coastal trading ship.
For those previously unfamiliar, tradition holds that the cover of the ACUA Underwater Archaeology Proceedings volume prominently display an historical image exhibiting a maritime theme-typically a postcard-that relates to the broader conference theme or venue city. This year the Proceedings cover design itself pivoted from the norm, albeit slightly. Inspired by Della Scott-Ireton of the Florida Public Archaeology Network, photographed by Annalies Corbin of the PAST Foundation, and designed by Jim Bruner of the PAST Foundation, the image (and its off-kilter orientation) pokes fun at the challenges of conducting underwater archaeological fieldwork in the time of COVID. After all, if we can't laugh at ourselves ...

Finally, I would like to thank Annalies Corbin, Dave Ball, and Toni Carrell for their continued dedication to publishing the Proceedings each year. I would also like to thank Kathryn Sampeck for providing the opportunity for ACUA authors to publish their work in the journal. Most of all, I would like to thank the authors, who so patiently navigated an entirely new Proceedings publication process with me and worked hard to develop their conference presentations into papers. Ultimately, I hope that the inclusion of the 2021 ACUA Underwater Archaeology Proceedings as a special section of Historical Archaeology draws more attention to the work of underwater, nautical, and maritime archaeologists and underwater cultural heritage.

Publisher's Note Springer Nature remains neutral with regard to jurisdictional claims in published maps and institutional affiliations. 